\title{
An indirect approach of estimating spawning fraction as applied to Sardinops sagax from northern Chile*
}

\author{
GABRIEL CLARAMUNT ${ }^{1}$ and RUBÉN ROA ${ }^{2}$ \\ ${ }^{1}$ Universidad Arturo Prat, Depto. de Ciencias del Mar, PO Box 121, Iquique, Chile. E-mail: gclaramu@cec.unap.cl \\ ${ }^{2}$ Universidad de Concepción, Depto. Oceanografía, Concepción, Chile.
}

\begin{abstract}
SUMMARY: The spawning fraction of fishes with multiple spawnings and indeterminate fecundity is normally estimated through biologically intensive and time-consuming histological procedures, such as the one based on the proportion of females with post-ovulatory follicles of 1 day of age. Alternative methods based on macroscopic observations of the gonads are desirable. We conceptualize the spawning fraction as an area under a normal distribution of females classified according to oocyte diameters in the more advanced batch. The area depends on the value of two parameters of the normal distribution (mean and standard deviation) and the diameter at which the oocytes start hydration, when they are ready to be spawned. This conceptualisation was applied to Sardinops sagax of northern Chile, for which additional knowledge allowed us to reduce the problem to specifying a single property of the normal distribution: the standard deviation. Calibration of the area under the normal curve against the spawning fraction derived from histological information yielded a calibrated standard deviation parameter in a monthly series spanning one year. This parameter in turn was statistically related to the gonadosomatic index, as a relative measure of gonadic development which is easy to obtain for any given fish population. Furthermore, the gonadosomatic index was shown to be a proper description of size-standardized gonadic development. The equation relating this index and the standard deviation was then used to predict the spawning fraction which was in close proximity to the histologically-derived spawning fraction. Through this approach the gonadosomatic index can be used for years in which no histological information is available, providing an indirect way to obtain the spawning fraction when a time series of the index is available.
\end{abstract}

Key words: reproduction, spawning, daily spawning fraction, sardine, Pacific.

\section{INTRODUCTION}

Annual egg production in fishes with multiple spawnings and indeterminate fecundity can be defined as the product of the number of discrete spawning events over a complete annual cycle and the average number of eggs released in each event. The number of spawnings per month in turn is estimated as the daily spawning fraction in a given month times the number of days. In an annual cycle, estimates for each month are necessary to obtain the number of spawnings per year. Normally, the

*Received December 9, 1999. Accepted July 17, 2000. spawning fraction is estimated through the proportion of females with post-ovulatory follicles of 1 day of age. However, this is a time-consuming and biologically intensive histological methodology which can only be applied with samples obtained over short periods. Two faster and simpler alternative procedures which have been proposed are: 1) macroscopic observations of the ovaries (Hunter et al., 1985; DeMartini and Fountain, 1981; Parrish et al., 1986) and 2) utilization of a statistical relationship between ovary weight and oocyte diameter in the more advanced batch (Claramunt and Herrera, 1994). The latter authors were able to estimate the daily spawning fraction during short periods of peak 
reproductive activity in Sardinops sagax from northern Chile using the proportion of females with ovaries with oocyte diameters of $650 \mu \mathrm{m}$ or larger (oocyte size at the onset of hydration). This proportion was in turn obtained indirectly through measurements of ovary weight. Hunter and Lo (1997) supported this approach by pointing out that with proper calibration, indices of periodic spawning fraction based on gonad weight might be used as a substitute for histological methods. Claramunt and Herrera's (1994) approach, however, was largely empirical and did not properly support its reliance on ovary weight. In this work we provide theoretical and statistical support to the approach, corroborate its relationship with relative measures of gonadic development, and apply it to a full annual cycle of Sardinops sagax of northern Chile.

\section{MATERIALS AND METHODS}

\section{Source of information}

The information was collected between April 1992 and March 1993 (Claramunt et al., 1994), and consisted of monthly sampling of fish onboard commercial fishing boats and during downloading of the refrigerated catch. A sample of 9251 females of between 24 and $30 \mathrm{~cm}$ total length was used to estimate daily spawning fraction through the counting of females with postovulatory follicles of one day age. Additionally, a subsample of 1178 female ovaries was used to determine the oocyte diameter frequency distribution in the more advanced batch and in the immediately lower batch by using a set of sieves in the range 200 to $1000 \mu \mathrm{m}$ with intervals of $50 \mu \mathrm{m}$. The ships fished between $19^{\circ} 10^{\prime}$ and $21^{\circ} 30^{\prime} \mathrm{S}$ approximately. The standardized ovary weight was computed through the familiar gonadosomatic index $I$ :

$$
I=100 \frac{G}{T-G}
$$

where $G$ is ovary weight $(\mathrm{g})$ and $T$ is total weight (g) of a given female .

\section{The method and its approximations}

In Claramunt and Herrera (1994) the proportion of hydrated females in the population is equated to the expected proportion of females with ovaries with oocyte diameters equal to or greater than a certain fixed level $H_{t}$, the oocyte diameter at the onset of hydration in month $t$. In the present work the expected proportion $F$ is derived from a normal distribution of females classified according to oocyte diameter $\mathrm{X}$ in the more advanced batch

$$
F_{t, \text { exp }}=\frac{1}{\sqrt{2 \pi \sigma_{t}^{2}}} \int_{X_{t}=H_{t}}^{\mu_{t}+3 \sigma_{t}} \exp \left[-\frac{\left(X_{t}-\mu_{t}\right)^{2}}{2 \sigma_{t}^{2}}\right] d X
$$

where the upper bound is constrained to be 3 units of $\sigma$ greater than the mean. Three parameters are needed to estimate the expected proportion: a) the mean $\mu$; b) the standard deviation $\sigma$, and c) the diameter at which hydration $H$ occurs. Claramunt and Herrera (1994) assumed a fixed value of 650 $\mu \mathrm{m}$ for $H$ in $S$. sagax. In the present analysis, we let this diameter vary on a monthly basis by measuring it through its relationship with oocyte dry weight, as found by Claramunt et al. (1994) with the same sample used here (Table 1). We assume here that the three parameters determining daily spawning frac-

TABLE 1. - Weibull function $O W=K\left(1-e^{\left(\frac{X}{S}\right)^{B}}\right) \quad$ parameters fitted to oocyte diameter $(X)$ and its relationship with oocyte dry weight $(O W)$

\begin{tabular}{|c|c|c|c|c|c|c|}
\hline Month & $K$ & $S$ & $a$ & $r^{2}$ & $n$ & Hydration Diameter $(\mu m)$ \\
\hline April & 0.03207 & 392.5 & 4.3374 & 0.77 & 121 & 654.9 \\
\hline May & 0.03489 & 398.8 & 5.0226 & 0.93 & 307 & 620.5 \\
\hline June & 0.04356 & 424.2 & 5.0049 & 0.94 & 277 & 661.1 \\
\hline July & 0.03975 & 420.7 & 5.6091 & 0.91 & 288 & 625.0 \\
\hline August & 0.04530 & 428.8 & 4.9764 & 0.93 & 269 & 670.0 \\
\hline September & 0.04586 & 420.9 & 4.8920 & 0.93 & 229 & 662.7 \\
\hline October & 0.03751 & 389.1 & 5.4578 & 0.93 & 206 & 584.5 \\
\hline November & 0.03251 & 366.6 & 5.5764 & 0.86 & 168 & 545.9 \\
\hline December & 0.03712 & 385.9 & 5.1679 & 0.93 & 124 & 593.1 \\
\hline January & 0.04439 & 420.2 & 4.1532 & 0.92 & 179 & 717.2 \\
\hline February & 0.04517 & 417.0 & 4.5774 & 0.93 & 179 & 677.3 \\
\hline March & 0.04207 & 393.2 & 4.9554 & 0.91 & 166 & 615.7 \\
\hline
\end{tabular}
for the total sample of females collected from April 1992 to March 1993 (Claramunt et al. 1994) 
tion may not remain constant with time. The problem as stated can be simplified by noting that the standard deviation or the mean can be expressed as a function of each other if a quantile (for example the lower bound of the normal distribution of oocyte diameters in the spawning female population, defined by $\left.l_{t}=\mu_{t}-3 \sigma_{t}\right)$ could be known. Plaza (1995) found that the mean diameter of the batch of oocytes immediately below the more advanced batch and the hydration diameter have the same temporal trend, with a temporally constant diameter difference of about $310 \mu \mathrm{m}$. If we assume that the mean size of oocytes in the lower batch represents a lower bound of the oocyte diameter distribution in the more advanced batch, then

$$
I_{t} \approx H_{t}-400
$$

where the $400 \mu \mathrm{m}$ figure is taken to give assurance that most of the area of the normal distribution in the more advanced batch is covered. Therefore, as an approximation the mean $\mu$ for each month $t$ would be:

$$
\mu_{t}=I_{t}+3 \sigma_{t}=H_{t}-400+3 \sigma_{t}
$$

where the mean is now expressed as a function of the standard deviation given that the lower bound is assumed as known. The monthly proportion of hydrated females in the population in Eq. (2) becomes

$$
F_{t, \exp }=\frac{1}{\sqrt{2 \pi \sigma_{t}^{2}}} \int_{X_{t}=H_{t}}^{H_{t}-400+6 \sigma_{t}} \exp \left[-\frac{\left(X_{t}-H_{t}+400-3 \sigma_{t}\right)^{2}}{2 \sigma_{t}^{2}}\right] d X
$$

where 3 further $\sigma$ units have been added to the upper limit of integration to cover almost the whole area of integration. Under this formulation, fluctuations of the population spawning fractions can be explained by fluctuations in the oocyte size at hydration and the standard deviation of the size of oocytes in the more advanced batch. Recall now that $H_{t}$ is known from its relationship with oocyte dry weight parameterized in Claramunt et al. (1994) (see Table 1). Given then the previously stated assumptions and approximations, the spawning fraction remains as solely dependent on the standard deviation of oocyte diameter in the more advanced batch.

Finally, for the complete annual cycle in the available sample we also applied the direct method of the proportion of females with post-ovulatory follicles of 1 day of age to estimate the spawning fraction on a monthly basis. Call this estimation $F_{t, P O F}$. Then the monthly standard deviations of Eq. (5) were fixed as those that would render $F_{t, e x p}$ identical to $F_{t, P O F}$ using Hastings' numerical algorithm (Zar, 1984) with the normal distribution in standardised form.

\section{The gonadosomatic index as a proxy variable}

In the method outlined above, we are able to estimate the standard deviation of the distribution of females classified according to the diameter of oocytes in the more advanced batch and from it the expected spawning fraction, when calibrated against the spawning fraction provided by a direct histological method. Our aim, however, is to be able to estimate the expected spawning fraction when no histological information is available. Therefore, with the results obtained from the sample at hand we searched for a statistical link between the calibrated standard deviation and another macroscopic gonadic process. The most common measure of macroscopic gonadic development is the gonadosomatic index (I) defined in Eq. (1), a measurement which is intended to represent gonadic development independent of the size of the fish and which is normally taken from routine sampling operations on a given population of fish under commercial exploitation. This is in fact the case of the $S$. sagax fishery in the north of Chile. When the relation between standard deviation and gonadosomatic index has been obtained, this relation is used to compute the expected monthly spawning fraction, which may be compared again to that observed through the histological method of postovulatory follicle. The gonadosomatic index, however, has its own problems as a sizestandardised measure and should be validated before using it with any degree of confidence (DeVlaming et al., 1982; Erickson, 1985; West, 1990). The validation involves examining the increase in gonadic weight as body weight increases, which should be linear for the index to compensate for fish body size. The approach suggested by DeVlaming et al. (1982) consists of classifying females according to maturity stages, performing linear regressions on each stage, and then comparing the different regression lines. Unfortunately, in order to estimate the intercepts this approach requires making extrapolations to immature, small-sized females not available in the sample. In general, 
extrapolations beyond the range of available data are not recommended in regression analysis (Zar, 1984). Furthermore, the definition of developmental stages in gonadic maturity involves a certain degree of arbitrariness, thus affecting the estimation of slopes. Therefore, in this work we have adopted a different strategy, which consists of taking advantage of the known statistical relationships between the mean diameter of oocytes in the more advanced batch, the weight of those oocytes, and the gonadosomatic index (Claramunt et al., 1993, 1994). Oocyte weight is defined here as the ratio between the weight of a subsample of ovarian tissue and the number of oocytes in the more advanced batch in that sample of ovarian tissue (Tanasichuk and Ware, 1987). We develop an algebraic model demonstrating that given the known statistical relationships, the derived relationship between ovary weight and body weight is linear for all stages of maturity taken at once.
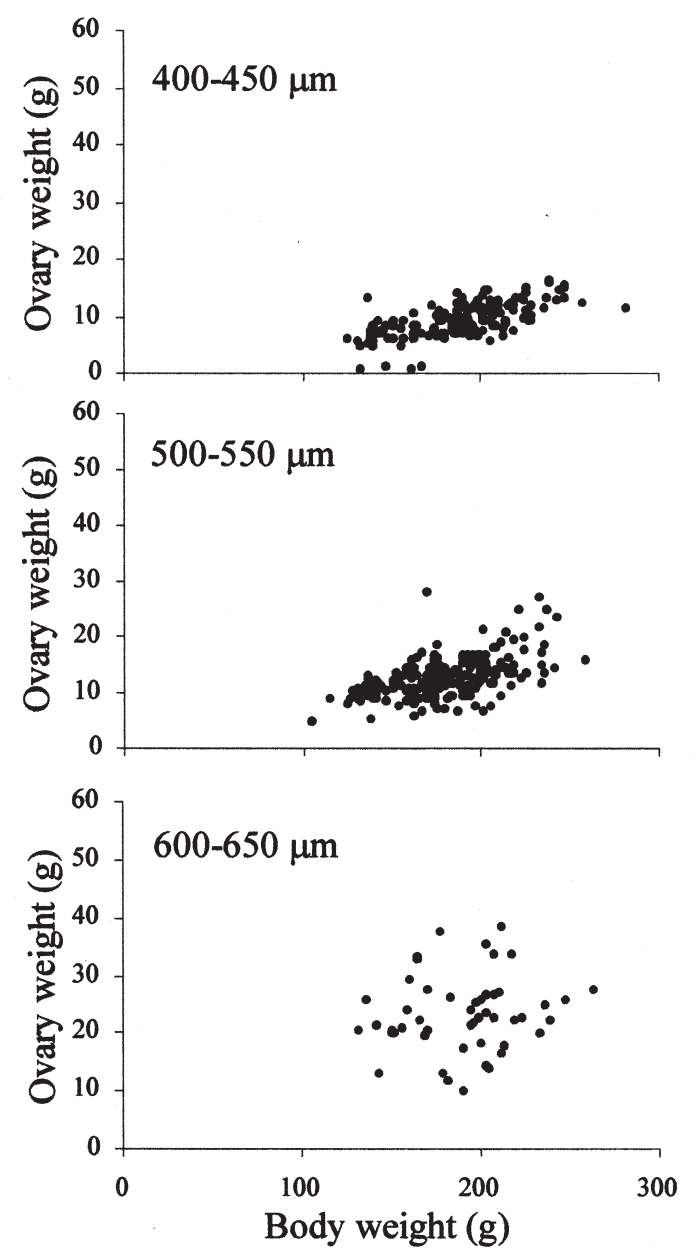

\section{RESULTS}

\section{Gonadosomatic index}

Claramunt et al. $(1993,1994)$ fitted a power relationship between mean oocyte diameter in the more advanced batch and the gonadosomatic index $I$

$$
I=a \cdot X^{b}
$$

and a similar relation with weight of those oocytes

$$
W=c \cdot X^{d}
$$

where $a, b, c$ and $d$ are parameters, for $S$. sagax from northern Chile. Now the number of oocytes in a given weight of ovary $(N)$ is the reciprocal of the weight of the oocytes, so it also has a power relation with oocyte diameter, though a negative one
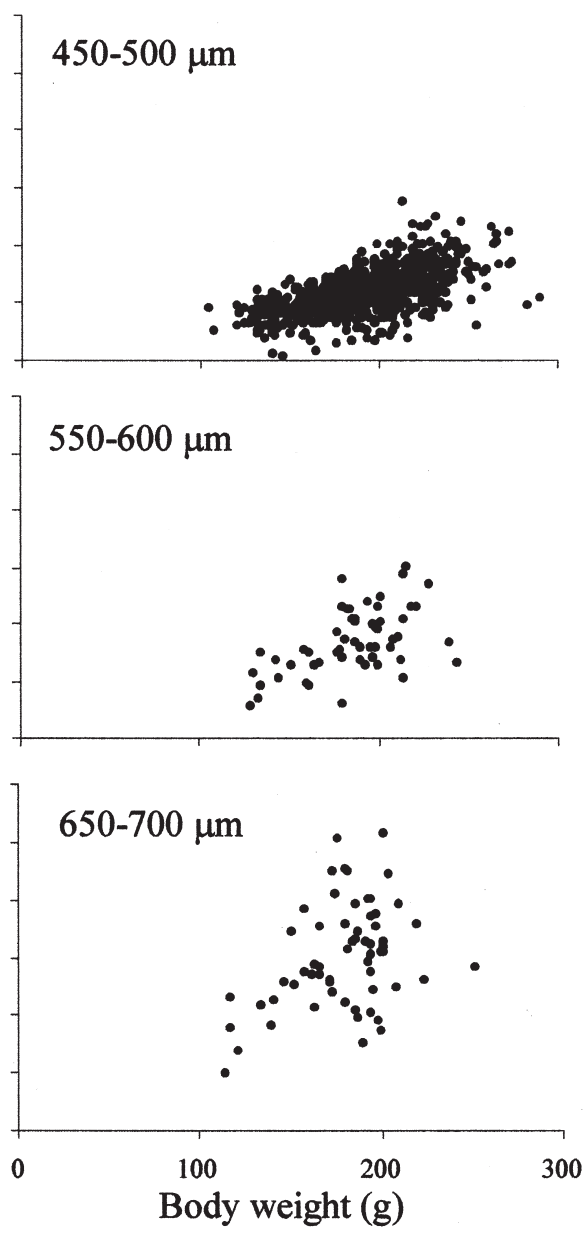

FIG. 1. - Ovary weight versus body weight for females of Sardinops sagax from northern Chile grouped according the mean diameter of oocytes in the more advanced batch $(\mu \mathrm{m})$. 


$$
N=\frac{1}{c} X^{-d}
$$

Solving for $X$ in Eq. 6, replacing the solution in Eq. 7, and returning $I$ to its definition in Eq. 1, yields

$$
N=q\left(\frac{G}{T-G}\right)^{-p}
$$

where $p=d / b$ and $q=(1 / c)(1 / a)^{-p}$. Define the new variable $Q$ which depends on the number of oocytes per unit weight of ovary

$$
Q=\left(\frac{q}{N}\right)^{1 / p}
$$

Then a bit more of algebra can show that the relationship between ovary weight and body weight is of the form

$$
G=\frac{Q T}{1+Q}
$$

which is linear in $T$ in all its range (and is zero when $T=0$ ) if $Q$ is independent of $T$. In fact, the ovary versus body weight relationship did present the
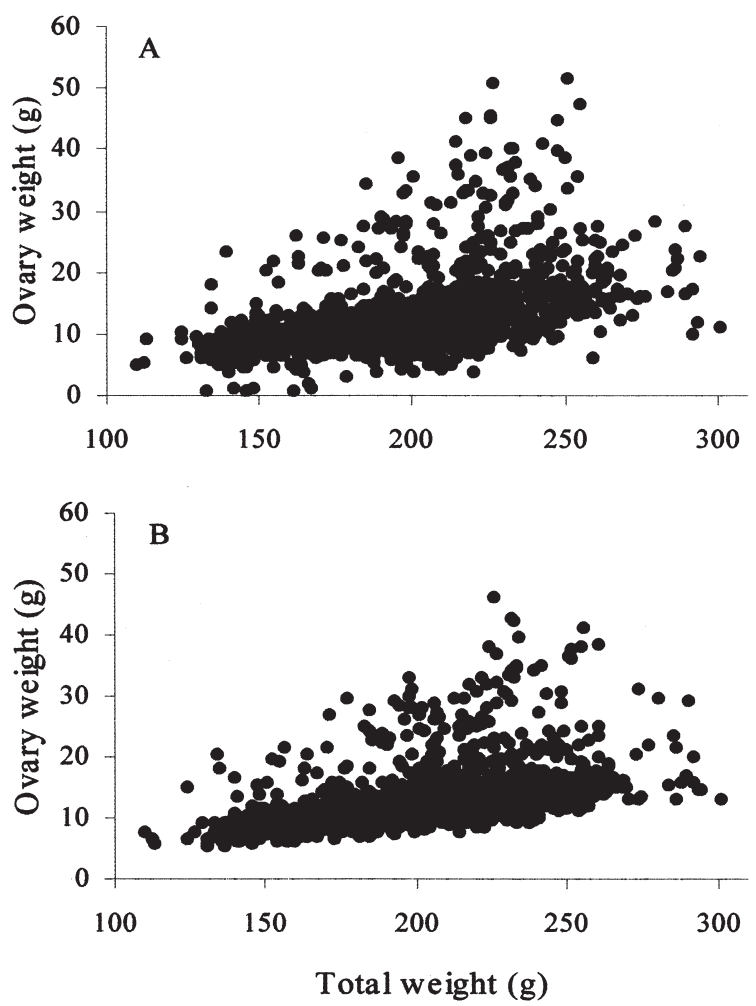

FIG. 2. - Observed (a) and estimated (b) ovary weight versus body weight for female Sardinops sagax from northern Chile. Estimated values come from Eq. 11 (see text) with estimated parameters (standard errors in parentheses) $\mathrm{q}=132.46(9.02), \mathrm{p}=1.31(0.03) . \mathrm{r}^{2}=$ 0.72 and $n=1178$.
TABLE 2. - Monthly spawning fractions from the histological method of postovulatory follicles $\left(F_{P O F}\right)$, calibrated standard deviations of the oocyte diameter distribution in the more advanced batch $(\sigma)$, gonadosomatic index $(I)$, and monthly spawning fractions $\left(F_{c a l}\right)$ as derived from the relationship between $\sigma_{\text {cal }}$ and $I$.

\begin{tabular}{lcccc}
\hline Month & $F_{P O F}$ & $\sigma_{\text {cal }}(\mu m)$ & $\mathrm{I}$ & $F_{\text {cal }}$ \\
\hline April & 0.094 & 92.667 & 3.063 & 0.014 \\
March & 0.018 & 78.478 & 3.527 & 0.021 \\
June & 0.063 & 88.299 & 4.823 & 0.052 \\
July & 0.083 & 91.216 & 5.388 & 0.072 \\
August & 0.090 & 92.150 & 6.413 & 0.115 \\
September & 0.094 & 92.666 & 5.759 & 0.086 \\
October & 0.076 & 90.242 & 4.029 & 0.031 \\
November & 0.016 & 77.756 & 3.337 & 0.018 \\
December & 0.044 & 84.997 & 4.818 & 0.052 \\
January & 0.083 & 91.217 & 5.754 & 0.086 \\
February & 0.134 & 97.378 & 6.718 & 0.130 \\
March & 0.075 & 90.099 & 5.132 & 0.063 \\
& & & & \\
\hline
\end{tabular}

expected linear behavior, except in the case of the later stages of development (oocyte diameter greater than $600 \mu \mathrm{m}$ ), where partially hydrated oocytes introduce excess variability into the relationship (Fig. 1). Furthermore, the linear model in Eq. 11 provided a good fit to the observed ovary weight versus body weight relationship (Fig. 2).

\section{Gonadosomatic index and standard deviation relationship}

The spawning fractions obtained through the histological method of postovulatory follicles and the monthly standard deviations of the oocyte diameter distribution obtained through the calibration procedure are shown in Table 2. This standard deviation and the gonadosomatic index $I$ show a clear positive linear relationship, which is very good when the first month in our data is excluded from the regression analysis (Fig. 3). The linear equation fitted to the standard deviation versus gonadosomatic index (Fig. 3) without April predicts values of the monthly spawning fraction which are very close to the values obtained through the histological method of postovulatory follicles, except again for April (Table 2). In fact, a further linear regression between the monthly spawning fraction calculated through Equation 5 with the standard deviation predicted by the linear function in Figure 3 versus histological spawning fractions for each month in the annual series has an intercept not significantly different from 0 (intercept $=0.003$; S.E. $=0.0199$ ) and a slope not significantly different from 1 (slope $=0.807$; S.E. $=0.2506)$. Thus, we can be confident that $I$ can 


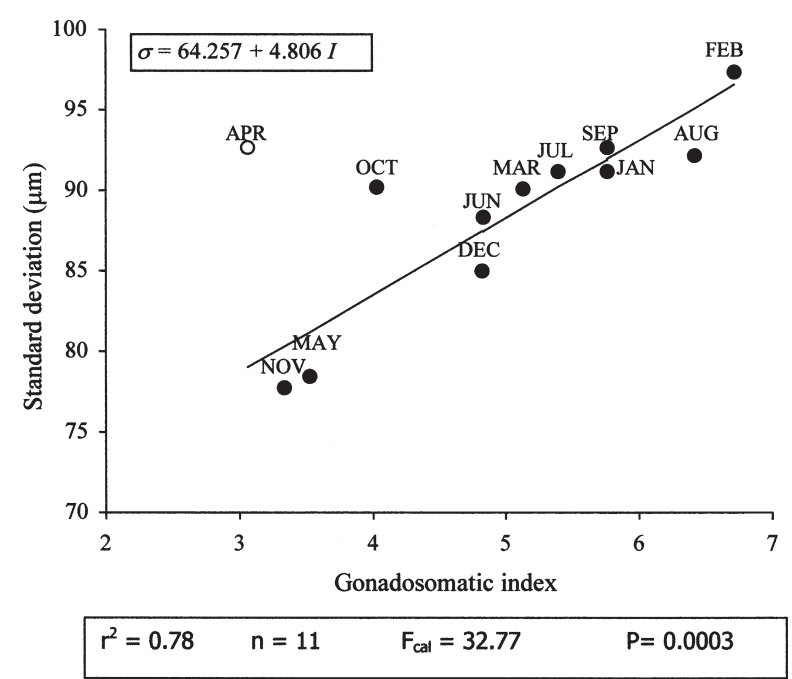

FIG. 3. - Relationship between calibrated standard deviation of oocyte diameter in the more advanced batch versus gonadosomatic index of female Sardinops sagax from northern Chile. Fit without April.

be used in $S$. sagax from northern Chile as a proxy for spawning fraction in years without histological information, through its relationship with the standard deviation in Figure 3, if we assume that the monthly variation in oocyte diameter distribution in the more advanced batch of the female population remains with the same attributes as in the yearly cycle covered by our sample.

\section{DISCUSSION}

The method that we have presented and applied here to Sardinops sagax from northern Chile provides a straightforward way to estimate spawning fraction on a monthly basis once it has been calibrated against histological information. It has the same conceptual basis as the hydrated ovaries method (Hunter and Macewicz, 1985) but it differs in that the spawning fraction is an expected proportion under a normal distribution, instead of a proportion of ovaries in a given state. The expected spawning fraction was calibrated for one year with histological data and then, assuming a temporal constancy in the relevant parameters, it can be applied as an approximation to other samples through the gonadosomatic index as a proxy variable. However, the use of the method through the gonadosomatic index can be questioned because the index itself presents some problems as a representation of sizestandardised gonadic development (DeVlaming et al., 1982; Hunter and Macewicz 1985; West 1990).
Its simple form (Eq. 1) assumes that gonad weight increases linearly with body weight in each maturity stage, an assumption that has to be checked. In our case we have shown through previously known statistical relationships (Claramunt et al., 1993, 1994) and some algebraic reasoning that if the relationship were not linear, then the number of oocytes per unit ovary weight would depend on body weight. This in turn would imply that the size of the oocytes would be dependent on body weight. Wallace and Selman (1981) have shown that the main determinant of oocyte diameter is the amount of yolk, and Claramunt et al. (1994) have shown that this amount is not dependent on body weight in $S$. sagax from northern Chile. It follows then that the number of oocytes per unit ovary weight does not depend on body weight, and then according to Eq. (11) gonadosomatic index is linearly dependent on body weight in each maturity stage. This algebraic reasoning is further corroborated by inspecting Figure 1 , which despite variability does not show any evidence in nonlinear behavior, and Figure 2, which shows that the algebraically developed linear model provides a good description of observed gonadic weight across the range of body weight. In our Equation (11), maturity stage is represented through the Q parameter, which depends on the number of oocytes per unit weight of ovary.

The method also depends on a proper knowledge of at least two values of the diameter distribution of oocytes: hydration diameter of oocytes in the more advanced batch and mean diameter of oocytes in the immediately lower batch. This latter diameter is used as a benchmark indicating a minimum bound in the diameter distribution of oocytes in the more advanced batch. Does this difference, which in the case of our application is $400 \mu \mathrm{m}$, remain constant throughout the year as new spawning events take place? There is some evidence backing this assumption. Firstly, yolk incorporation into the oocytes begins at most at $200 \mu \mathrm{m}$ diameter (Herrera and Claramunt, 1990; Macewicz et al, 1996; Hay et al., 1987; Tyler and Sumpter, 1996). Secondly, the immediately lower batch of oocytes is in the range of 200 to $450 \mu \mathrm{m}$ diameter (Claramunt and Herrera, 1994), which according to the dry weight information in Table 1 corresponds to the size range with a greater rate of growth (close to half asymptotic dry weight). This indicates that yolk uptake would result in parallel growth schedules in the immediately lower and the more advanced oocyte batches. Therefore, the diameter difference between the two batch- 
es would most likely remain constant, in agreement with Tascheri and Claramunt (1996), who found that the dry weight of the lower batch follows the same trend as the more advanced batch.

In the relationship between the gonadosomatic index and the standard deviation of oocyte diameter distribution of the more advanced batch, the month of April appears as a clear deviate in an otherwise fairly good positive linear dependency. This was caused by a low gonadosomatic index but a high spawning activity in that month, as indicated by the histological method, in clear contradiction with previous studies which have identified this month as a resting period for $S$. sagax from northern Chile (Serra and Tsukayama, 1988; Oliva et al., 1989). This deviation from the overall trend might have been related to the 1991-1992 El Niño event, which caused water temperature anomalies as high as $4.2^{\circ} \mathrm{C}$ above normal in March 1992 (Fuenzalida, 1992). It is known that high temperatures can accelerate postovulatory follicle degeneration, possibly leading to an erroneous age classification (Fitzhugh and Hettler, 1995).

The annual reproductive output of fishes with multiple spawnings and indeterminate fecundity depends on the number of eggs released in each spawning event and the number of such spawning events during a year. This latter number is in turn the daily spawning fraction in a month times the number of days and summed up during an annual cycle. According to Parrish et al. (1986), the best approach for estimating spawning fraction is a combination of detailed and time-consuming histological analyses on a few fishes and macroscopic indices of reproductive activity from a large number of fishes. The method applied here falls neatly into the category described by these authors, using monthly periods as the grain of the analysis, and has proved to be useful for the case of $S$. sagax from northern Chile. In fact, a further application of the method might take advantage of a large database of gonadosomatic indices for this species, in order to build a time series of reproductive output with a historical perspective.

It might be interesting to check whether this methodology can be applied to other fishes with multiple spawnings, which would need a proper calibration with daily spawning fraction from direct methods, either histological or based on hydrated ovaries. Further, the existence of a relation between calibrated standard deviation of the diameter distribution of oocytes in the more advanced batch and the gonadosomatic index should be verified, in order to use the latter as a proxy variable. The validation of the index is not a critical point if it can be proved that the previous relation is significant. The assumptions that should be adopted or backed with additional information are: 1) the population of mature females, classified according to the mean diameter of oocytes in the more advanced batch, is properly described by a normal distribution; 2) the lower bound of this distribution represents post-spawning females; 3) if there are variations in the hydration parameter, the lower bound of the distribution varies correspondingly; and finally, as implied by the previous assumption, 4) there are no variations in the in the size of the oocytes because of the body size of the females.

\section{ACKNOWLEDGMENT}

We thank G. Herrera for his extensive lab work in histological analysis of thousands of fishes. J. Hunter provided valuable stimulation to continue in this line of research. This paper benefited from discussions with R. Quiñones. Funded by FONDECYT grant 92-307 to GC.

\section{REFERENCES}

Claramunt, G., G. Herrera and P. Pizarro. - 1993. Fluctuaciones de la fecundidad parcial en sardina española (Sardinops sagax) durante la época principal de desove de 1990, en la zona norte de Chile. Sci. Mar. 57(1): 9-14.

Claramunt, G. and G. Herrera. - 1994. A new method to estimate the fraction of daily spawning females and the numbers of spawnings in Sardinops sagax in northern Chile. Sci. Mar., 58(3):169-177.

Claramunt, G., G. Herrera, and P. Pizarro. - 1994. Producción potencial anual de huevos por tallas en Sardinops sagax (Jenyns, 1842) del norte de Chile. Rev. Biol. Mar., Valparaíso. 29(2): 211-233.

DeMartini, E.E. and R.K. Fountain. - 1981. Ovarian cycling frequency and batch fecundity in the queenfish, Seriphus pollitus: Attributes representative of serial spawning fishes. Fish. Bull., 79(3): 547-560.

DeVlaming, V., G. Grossman, and F. Chapman. - 1982. On the use of the gonosomatic index. Comp. Biochem. Physiol. 73A: 31-39.

Erickson, D.L., J.E. Hightower and G. Grossman. - 1985. The relative gonadal index: an alternative index for quantification of reproductive condition. Comp. Biochem. Physiol. 81A(1): $117-120$.

Fitzhugh, G.R. and W.F. Hettler. - 1995. Temperature influence on postovulatory follicle degeneration in Atlantic menhaden, Brevoortia tyrannus. Fish. Bull., U.S. 93(3): 568-572.

Fuenzalida, R. - 1992. Anomalías oceanográficas y metereológicas durante el desarrollo de El Niño 1991-92 en la zona de Iquique (20¹8’S). Investigación Pesquera, (Chile), 37:67-72.

Hay, D.E., D. N. Outram, B.A. McKeown and M. Hurlburt. - 1987. Ovarian development and oocyte diameter as maturation criteria in Pacific herring (Clupea harengus pallasi). Can. J. Fish. Aquat. Sci. 44: 1496-1502. 
Herrera, G. and G. Claramunt. - 1990. Estimaciones de la fecundidad parcial y frecuencia de desove de Sardinops sagax durante 1987 y 1988, en el norte de Chile. Revista de Invest. Cient. y Tec., Serie: Ciencias del Mar, Universidad Arturo Prat, 1: 55-68.

Hunter, J.R. and B. Macewicz. - 1985. Measurements of spawning frequency in multiple spawning fishes. In: R. Lasker (ed.) An egg production method for estimating spawning biomass of pelagic fish: Application to the northern anchovy, Engraulis mordax. NOAA Tech. Rep. NMFS 36: 79-94.

Hunter, J.R., N. Lo and R. Leong. - 1985. Batch fecundity in multiple spawning fishes. In: R. Lasker (ed.) An egg production method for estimating spawning biomass of pelagic fish: Application to the northern anchovy, Engraulis mordax. NOAA Tech. Rep. NMFS 36: 67-77.

Hunter, J.R. and N. Lo. - 1997. The daily egg production method of biomass estimation: some problems and potential improvements. Ozeanografika. 2:41-69.

Macewicz, B.J., J.J.C. Castro, C.E. Cotero and J.R. Hunter. - 1996. Adult reproductive parameters of Pacific sardine (Sardinops sagax) during 1994. CalCOFI Rep., 37: 140-151.

Oliva, J., J. Barañados and M. Tirado. - 1989. Determinación de la fecundidad y frecuencia del desove de la sardina (Sardinops sagax), 1986. Memorias del Simposio Internacional de los Recursos Vivos y las Pesquerías en el Pacífico Sudeste, Viña del Mar, Chile, 9-13 mayo. 1988. Comisión Permanente del Pacífico Sur (CPPS). Revista Pacífico Sur (número especial): 341-348.

Parrish, R. H., D.L. Mallicoate and R.A. Klingbeil. - 1986. Age dependent fecundity, number of spawning per year, sex ratio and maturation stages in northern anchovy. Fish Bull., U.S. 84(3): 503-517.

Plaza, G. - 1995. Caracterización intra-anual del desplazamiento modal de ovocitos en Sardinops sagax Jenyns, 1842 (Pisces: Clupeiformes) en el norte de Chile. Thesis, Universidad Arturo Prat, Iquique, Chile. 84 pp. [Available from Arturo Prat University, Casilla 121, Iquique, Chile].

Serra, R. and I. Tsukayama. - 1988. Sinopsis de datos biológicos y pesqueros de la sardina, Sardinops sagax en el Pacífico suroriental. FAO Sinop. Pesca, (13) Rev. 1:60 p.

Tanasichuk, R.W. and D.M. Ware. - 1987. Influence of interanual variations in winter sea temperature on fecundity and egg size in Pacific herring (Clupea harengus pallasi). Can. J. Fish. Aquat. Sci., 44: 1485-1495.

Tascheri, R. and G. Claramunt. - 1996. Aproximación a los cambios intra-anuales en el contenido de energía del ovario de sardina (Sardinops sagax Jenyns, 1842) en el norte de Chile. Invest. Mar., Valparaíso, Chile. 24:51-66.

Tyler, C.R. and J.P. Sumpter. - 1996. Oocyte growth and development in teleosts. Rev. Fish Biol. Fish., 6: 287-318.

Wallace, R. and K. Selman. - 1981. Cellular and dynamic aspects of the oocyte growth in teleosts. Amer. Zool., 21:325-343.

West, G. - 1990. Methods of assessing ovarian development in fishes: a review. Aust. J. Mar. Freshwater Res., 41: 199-222.

Zar, J.H. - 1984. Biostatistical analysis. 2nd. Ed. Prentice-Hall, Englewood Cliffs, New Jersey.

Scient. ed.: G. Pequeño 